\title{
Empowerment in Academic Cultures: Whose Responsibility is It?
}

\section{Lance C. Buhl}

\section{Introduction}

This is an essay - cast first as an address - on visions and values, cultures and communities, power and paradigm. It is about leadership, really. And our responsibility as academic leaders who are called "developers" to create and maintain empowering institutions of higher education. The alternative title for the essay is EMPOWERMENT IN ACADEMIC CULTURES: IF WE WON'T, WHO WILL? That probably more accurately reflects my concerns.

Harold Bridger of Tavistock Institute in London established the theme around which I will explore these issues in 1978 at the First European Forum on Organization Development (Aachen). In the address with the tidy little title, "The Kind of 'Organizational Development' Required for Working at the Level of the Whole Organizational Considered as an Open System," Bridger aptly describes one facet of our reality in colleges and universities:

One of the most critical needs in organizational life has become that of ensuring that when a pilot or innovative group has developed a form of work life eminently relevant to its function and purpose, it should not be allowed to wither away or become isolated in its wider organizational environment praise its worth but prevent diffusion of its values and processes on rational grounds combined with unrecognized destructive thinking. 
How many professional development programs have passed by the boards in the last ten years! Indeed, a good part of what we face is how to nurture those programs set up to nurture heal thy teaching/learning interactions, which in themselves are the very model of mutual empowerment. In considering why we must struggle so hard, not to begin programs but to maintain their existence (much less their vitality), I think we need to look beyond economic woes. Money is always scarce. The truth of our difficulty lies in cultural beliefs, fairly general across higher education, that are inimical to any dynamic conception of development itself. The fact is that most academics either do not believe that people - students, colleagues, others-really "develop" or they do not act consistently with such a belief if they hold it.

Now this sounds like harsh judgement. I suppose it is. Much of what follows here will also sound severely judgmental. Because of that, I need to affirm that I am in fact an optimist about human beings. I believe that most people most of the time want to do well and usually fulfill that wish. I'm not quite up to Will Rogers' standard, but I can say that with very few exceptions I haven't met an academic whom I did not or could not like. More, I believe that most academics most of the time want to do well in the classroom, would like to promote (or at least be associated with) learning in most students, and are sincerely committed to the advancement of knowledge and a just society. And, finally, I believe that next to teaching students promoting professional development- -in teaching, in service, in scholarship and creativity, in administration and leadership-is potentially one of the most empowering kinds of work there is to be done in this society. I am aware, too, that my judgements run the risk of discouraging men and women who are new to professional development efforts. I hope that my words serve more to forearm then to forebear. Frankly, in this case I do not know how to reconcile my commitment to positive reinforcement of important work (as a principal of practice) with my perhaps stronger commitment in this case to intellectual honesty. The alternative to speaking up is to bite my tongue. I guess I don't have a strong commitment to self-mutilation.

Enough of apology! 


\section{The Theme Encapsulated}

Good form suggests that I tell you what I will say, say it (next section), and tell you what I have said. If I had one sentence to telegraph and summarize all that I have to say, it would be: the reason professional development in teaching is a) so difficult to maintain and b) results in so little is that developers on the one hand and most academics (whatever the institutional context, on the other use the same words to describe very different concepts of education. This message has several parts, three to be exact:

1. In assessing what we "developers" have done and need to do, we should think in terms of the larger culture of higher education. That is, we should examine the assumptions and rules, norms, and roles academics maintain. We should be concerned with the purposes of that culture. From the cultural perspective, "developers" are probably failing. We have not had much impact on ruling attitudes and behaviors, certainly not enough on a broad enough basis to contribute to creating or maintaining a developmental or an empowering culturewhat F. Lee Knefelkamp, following Erik Erikson, calls "generativity" or "the capacity and the ability to care for that which we have created: children, knowledge, students, faculty, staff, entire institutions." It would be comforting to think otherwise, but I am compelled to agree with Knefelkamp in her fear that colleges and universities are "in danger of becoming a higher education community characterized by non-generativity and by inability to hear each others' voices." Professional development, for all of its latest reincarnation since the late 1960's, has done little to reverse, even to stem, this outbound tide.

2. It is my personal judgement, and the clear implication of Knefelkamp's observation about non-generativity, that the cultures of most colleges and universities-indeed, the general culture of higher education in this country -are inherently disempowering. In fundamental ways they contribute to perpetuating social and intellectual limitations - on students, on faculty, on staff, on administrators. Rather than fulfilling the liberating promises we all say higher education should achieve, common educational practice and belief undermines human development. The root of our failure to have an impact on that common educational practice and belief structure lies in 
misperceiving the terms of the prevailing - the disempowering-cultural paradigm. In fact, we fail to understand that it is a different paradigm than the one which developmental notions about education describe. In our misunderstanding and misperceiving, we may be colluding in perpetuating the opposing paradigm and the culture it serves.

3. Our challenge as developers is to accept the possibilities of leadership. We must become powerful in a very special sense. And we must begin by acknowledging that we hold a very different cultural paradigm than the prevailing one. We need to spell that alternative vision out, use our special knowledge and technologies to train faculty and administrators in it, and make more effective use of our networks-POD in particular-in order to become effective academic leaders.

\section{Taking the Cultural Perspective}

Why take a cultural perspective at all? Don't we have enough to worry about just to keep our shops going without getting het up about whole cultures?

The answer to these questions starts with an acknowledgment that the very reason the contemporary wave of professional development in higher education got underway was that something was missing in the academic culture. More to the point is the fact that the current academic culture forms the topic of this year's POD conference-that is not accidental. For all the fatuousness in the notion that the 1970s formed the Me Decade, an Age of Narcissism in Christopher Lash's words, there is in fact something to the idea that culture and community suffered a setback in the early 70 s and are once again forcing their ways back into the center of our attention. The decision by the Planning Committee to organize this year's conference around those notions reflects appropriately enough, stirrings in the larger American culture.

Arnold Brown, in his article called "The Age of Osiris: Tumult and Transformation" used the Egyptian deity Osiris as a metaphor for what the 1970s have meant. Osiris in ritual was torn to pieces and reborn annually as a way of explaining the cycles of life on the Nile 
to the ancient Egyptians. Brown argues that we, to, may have been in the midst of a "pre-transformation" over the past decade. In reaction to the failure of traditional institutions and the still uncertain shape of new ones, Americans quite naturally spurned the conventional and, somewhat schizophrenically, resorted to their own individual resources. Osiris reborn - of a general renaissance of respect for broader social contexts and responsibilities.

Daniel Yankelovich, the prominent pollster and cultural critic, also gives testimony to a similar pattern. He argues that the 1950 s was ruled by the ethic of self denial and the 1960 s and 70 s by the ethic of self-fulfillment. If all the signs registered in peoples' responses to pollsters' questions are to be believed, the 80 s will shape up to be an age of the ethic of commitment. Community will play a large role.

People-academics-will find meaning in the cultures in which they live, work, and will exit this existence.

The preeminent roles of the cultural contexts and their relevant ethics forms the central message of the most sensible of management studies of Japanese business. These studies suggest that the rash of the greatest and most successful Japanese firms - indeed, the most enduringly successful American firms - got that way because of the coherence and strength of their internal or organization's philosophy, ethic and modes of socialization.

The striking thing about these philosophies is their simplicity and moral moorings. Richard Pascale and Anthony Athos, in their very important study of The Art of Japanese Management, conclude that "the best firms link their purposes and ways of realizing them to human values as well as to economic measures like profit and efficiency." (Pascale and Athos, p.44). For example, IBM seriously stresses the continuing relevance of founder Thomas Watson's code of corporate philosophy:

1) Respect for the individual. Respect for the dignity and the rights of each person in the organization.

2) Customer service. To give the best customer service of any organization in the world.

3) Excellence. The conviction that an organization should pursue all tasks with the objective of accomplishing them in a superior way. 
From these, Pascale and Athos observe, follow a set of principles for management that include enlarging the capabilities of IBM people through job development and the opportunity to find satisfaction in their tasks.

There is in these observations and the IBM example a message for higher education. Compare the IBM philosophy and attendant set of management principles to the long tortuous, self-righteous, and basically all but ignored mission statements, catalogue philosophies, and other PR texts of most colleges and universities. Oh, for some sincere, simple, behaviorally meaningful simplicity! I think of the very positive and altogether rare example of a retiring college president who, at a recent summer convocation for all staff members, asked two students to come up to the podium to stand with him for a moment. He pointed to the two and said to the staff, "These are two of our students. Please do not fold, spindle or mutilate." Corny? Maybe. It was nevertheless wonderfully refreshing to me to hear that simple metaphorical affirmation of the centrality of students to the mission of higher education. It's one that bears repeating titurally and often.

All the reemphasis on organizational cultures and ethics is an intriguing vindication of what the seminal thinkers about human behavior in complex organizations-Argyris, Likert, McGregor, McClelland - have urged all along. Rensis Likert, for instance, maintains that the mechanisms which organizations and societies rely on for dealing with conflict are true indicators of the level of their cultural sophistication and maturity. Those which legitimize conflict, value it, seek productive and humane ways of resolving it, and work to maintain the dignity and participation of all stakeholders in the aftermath of decisions are healthful organizations. They promote creativity and growth. It should be sobering that academic institutions as a class do not have very sophisticated mechanisms for handling conflict in Likert's studied opinion.

Not only should we attend to the institutional cultures in which we mange "developmental" efforts, but we should look to the broader, societal cultural context as well. As self-styled developers, how can we fail to be concerned about the health of democratic institutions and of the civil libertarian tradition? Our ideas about learning, growth, human cycles of development, and the free inquiry out of which such 
radical notions have grown have their roots and continue to depend for their sustenance on the cultural context of constitutional democracy. What colleges and universities do and produce profoundly affect the future of the body politic. Pure self-interest alone should tell us that we must have literate people capable of independent judgement and problem-solving, people, moreover, who value free inquiry and individual self-fulfillment. To be capable of exercising independent judgement and valuing, as a matter of practice, free inquiry, citizens need something more than simply to hear about the civil libertarian tradition. They need to be socialized in it. They need to have real experience of it in academic institutions.

Considered in the broader cultural context, the true mission of professional; development translates into ensuring that the conditions for learning (the faculty's responsibility) and the conditions for teaching (the administration's responsibility) reflect and foster the civil libertarian tradition.

\section{Development and the Disempowering Paradigm}

The fate of most collegiate professional development programs, both formal and informal, is a good illustration of the conundrum suggested by Harold Bridger. They tend to be short-lived and, in terms of the cultural patters of their institutions, inconsequential. There are numerous instances around the country of pioneering faculty development programs falling under the budget axe. No one even suggests that they have been eliminated because their work is done. On the contrary, they were just beginning to have an impact of any consequence. They died for lack of support. They were "marginal" to their academic cultures.

To some extent, we professional developers bear some of the responsibility. There is a disheartening tendency-I have seen it among us all across the nation-to have expectations for impact that are entirely unrealistic when judged against the kind of programming we undertake. We offer workshops and newsletters and imagine that faculty will change their teaching behaviors significantly. Or, we individualize our efforts through intensive consulting with a few 
faculty and expect that teaching and learning across an entire departmental curriculum will improve measurably. Or, we work with an entire department and think that the whole college will become more responsive to student learning requirements. In short, we violate pretty basic functional relationships between programming and impact, as illustrated in Table I.

IMPACTS

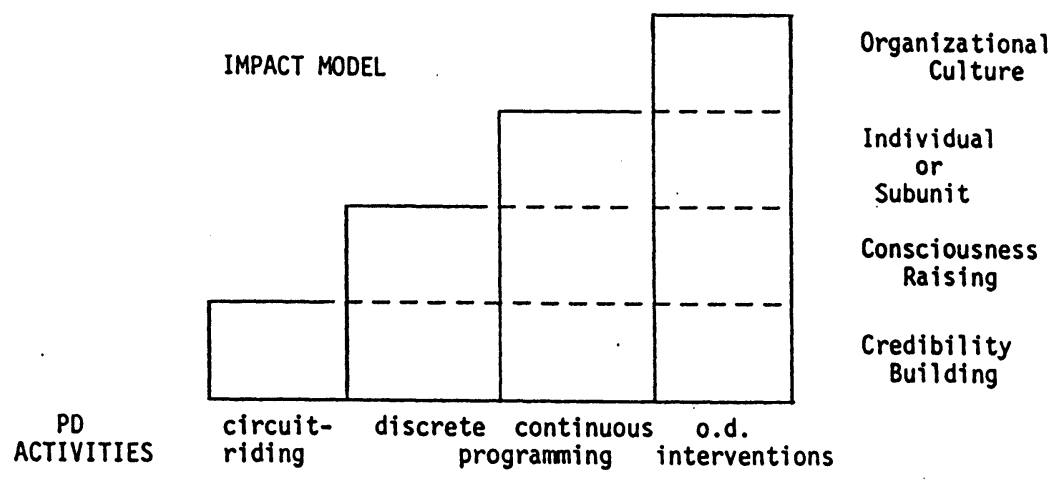

Although the data about the operation of professional programs is not extensive nor recently updated, what there is suggests that most programs operate principally in the discrete programming mode.

But the underlying cause of our failure to have impact lies not with us but in the cultures of most colleges and universities. To a certain extent, the literature on social change prepares us to expect a tough time in getting our message across. Men and women in complex organizations resist efforts which call for behavioral changes. But the resistance thesis is not adequate, in my judgement, to explain why development has had so little impact. I think we need to look at cultural assumptions, prevailing ethics. When we do this we begin to get a sense that the lack of receptivity is a function of a disempowering ethic which is so persuasive as to be paradigmatic.

The best and most convincing evidence about the extent and nature of the paradigm comes from the most cursory observation of 
predominant classroom practices. I trust I need not review the studies on student experience of college or of teaching practices for members of POD. But if doubt about all of this exists, I suggest that the doubter undertake his or her own survey of conditions as they exist in most classrooms on the campus. Do not be surprised if the overwhelmingly prevalent pattern is of one-way communication, passive in-class learning behaviors among students, lack of clarity about learning objective grading procedures, and grading criteria, almost no individualization of teaching/learning interactions, and haphazard organization of testing procedures.

Whether the paradigm which this pattern or teaching behavior underscores is intentional or not, it is fundamentally subversive of human development, democracy, and the civil libertarian tradition. That is, most students' experience of most courses across the entire undergraduate educations is framed by a set of faculty assumptions and behaviors that is medieval in spirit: learning is a mystery, that any but the brightest learn at all is a miracle, and all determinations of what constitutes meaning are controlled by the authority of the priesthood of scholars. The paradigm is best represented by the shape of the Gausian or normal distribution curve, illustrated in Table II.

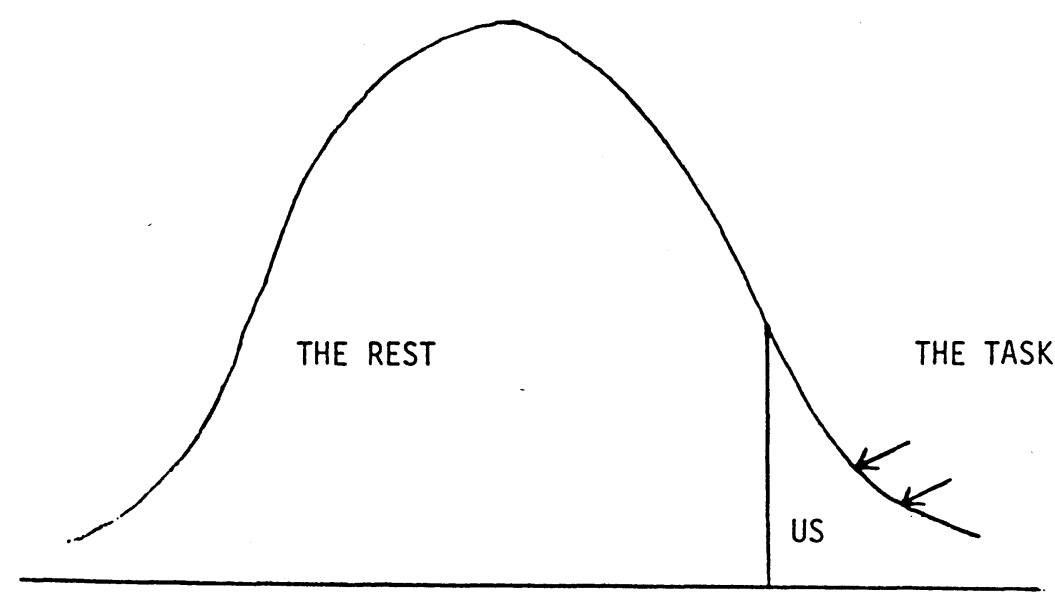


Think of the ubiquity of this model as a controlling metaphor for grading, in faculty commentary on students, in administrators' descriptions of faculty, in what passes for promotion and tenure evaluations and merit systems. A few are bright and excellent, most are adequate and average, and a few are dullards and hopeless. Once tagged, the student or the faculty member has one hell of a time demonstrating that he or she is anything else but. It is the Procrustean nature of the paradigm that is most antithetical to developmental values. I am reminded of Maurice R. Stein's commentary on the contribution of William James to American psychology and American culture. The "main point of James's approach to psychology," says Stein, "was the injunction that the tendency to categorize experience prematurely, and particularly, to categorize prematurely the meaning of other peoples' experience, is the greatest threat to full human existence." The prevailing disempowering paradigm in higher education does nothing if it does not categorize most students' experience, meaning, and capabilities prematurely. Indeed, the very violation of the Jamesian injunction lies in the inherently disempowering nature of the Gausian curve applied insistently, indiscriminately, and so without relationship to adequate data throughout higher education.

The paradigm confounds teaching for learning and thwarts efforts to change educational practice. The conception of teaching it allows in non-dynamic. Teaching is basically, therefore a gatekeeping function. It is unidimensional relative to teaching methodologies. It places no premium on honest evaluation; adequate to the self-justifying task of evaluation is the operation of a simple input-output model of measurement. So many books assigned, so many lectures given, so many quizzes and tests and papers specified equals a nearly normal distribution of grades. Evidence of learning (which "of course" is intangible anyway) is beside the point. The model is content-oriented almost exclusively. Process is faddish at best, a waste of time at worst. By definition, the model is extremely elitist. It is really any wonder that Patricia Cross notes that the gap between the "haves" and the "have nots" in higher education is increasing? By that token alone, the model subverts the development of anything like a real academic community; for, there is little interdependence among individuals possible and, worse, as Knefelkamp has pointed out, the model enter- 
tains very little in the way of caring behaviors. And, finally, like the other model or paradigm I will share with you shortly, this one is perfectly self-fulfilling.

I for one am not surprised that so prestigious a member of higher education's establishment as Clark Kerr concludes that colleges and universities do not do much more than help most students from slipping into greater scientific, cultural, political, and social illiteracy than when they left high schools. If such is the case, it augurs ill for the future health of the democratic tradition. Higher education may form a good example of what in medicine is called the "iatrogenic problem"- a pathology or illness resulting from or caused by the physician. Since it is illusory to count on any priesthood to reform itself, the question I posed as the title of this essay seems apropos. Let me rephrase it. If we won't empower, who will?

I have concluded that we are not yet an empowering force. The root of our failure to be such is that we have not recognized the disempowering paradigm for what it is and how tightly it grips higher education. In a sense, we have colluded in sustaining the disempowering paradigm despite our belief in an alternative one. We have accepted as a true bill the priesthood's civil libertarian and developmental rhetoric. We have not applied fully Chris Argyris' critically important distinction between "espoused theories" and "theories in practice." In fact, faculties (most obviously liberal arts education, and law faculties) deliver two messages to their students. The content message tends to affirm civil libertarian, egalitarian, and democratic values. The process message-how classrooms and courses are run by faculty members-affirms medieval values. I believe that the process message, because it is experiential, is at least powerful as the content message. I have a hunch that it may be more powerful.

Our collusion stands as a barrier between us and taking up a legitimate leadership role in academic life. That role, I submit, necessarily calls for advocacy on behalf of the development tradition and of the faculty who attempt to make it a reality in their courses. Yet our self-descriptions ignore advocacy in favor of an exclusively serviceoriented and reactive mission. Seldom, moreover, do our published descriptions of what we do reference the larger culture context. Thus, we speak of being change agents, but few of us have accepted the real 
burdens and consequences of what culturally relevant change imposes in terms of political sophistication. We are, by and large, political babes in the woods. Like most Americans we shy away from the thought that power is significant, natural, legitimate, and necessary as a tool for social good. Certainly we fail to understand that decisionmaking in higher education is very political. Jeffrey Pfeffer of Stanford, in his recently published and important examination of Power in Organizations argues that there are five conditions which, when present, place power into play: interdependence of people and functions, heterogeneity of goals, high "issue importance," and dispersal of power. Can anyone doubt that, for faculty development programs, all five of these conditions exist?

\section{Taking Up the Empowering Paradigm}

For all the pessimism that I have appeared to spread so liberally, I remain optimistic about the professional development mission. Apart from the fact that I am, by nature, an optimist, the more substantial reason is that we possess a very useful and important alternative paradigm. It can be transforming, if only because it has not been tested yet. Faculty by and large have not been asked to consider the implications of the dominant paradigm and to test it against the alternative. In short, we have not really forced a values clarification exercise in higher education.

In outline form the paradigm has been with us since early 1950 s. Pictorially, it was suggested first by Robert Tannenbaum. Its psychological dimensions were first explored by the psychologist Richard de Charms. It is presented in Table III.

In its early presentations, it had a static character. Really it is a very dynamic educational model, one well worth careful, continuing exploration.

The model, in essence, is an idealized representation of all personal power relationships, situations in which one party has more power than another. Its dynamism derives from the recognition that any system is goal-seeking, that the subordinates in the situation present themselves with a variety of degrees of socialization and skills, that the superior in the situation has in fact a wide variety of behavioral 


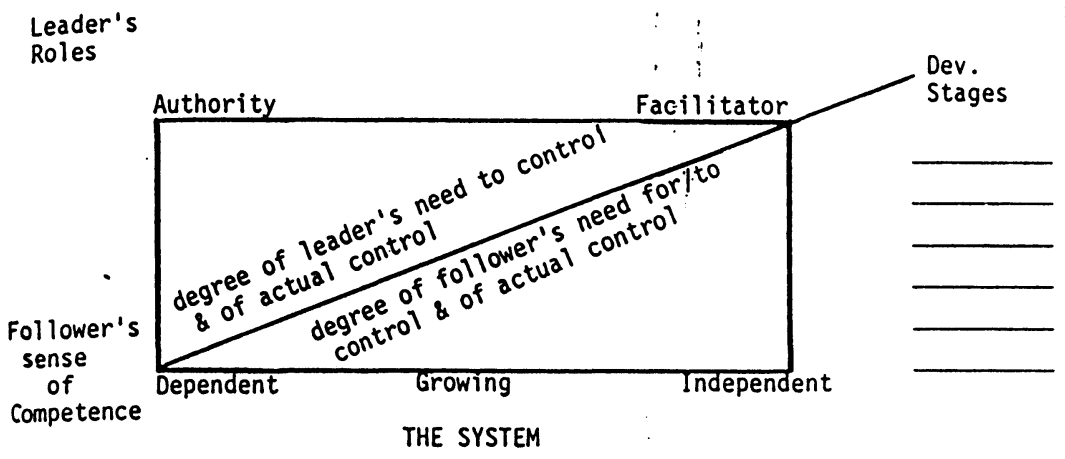

options for guiding subordinates' socialization, and that the effectiveness of the superior as a leader for most subordinates is a function of his or her appropriate reading and matching of subordinate developmental needs and motivational techniques. To be specific, the instructor of an introductory survey course taken by non-majors must recognize at a minimum that most of the students need significantly more authoritative organizing of the situation than do majors in a more advanced course in the subject. The underlying strategy for all instruction, however, is to provide each subject with sufficient opportunities for guided practice in each of the cognitive, effective, and/or psychomotor skills which form the important learning objectives of the course. The most common instructional mistake is either misreading the skill level and needs of the student or confusing lower level cognitive behaviors (memorizing solutions the professor develops to difficult problems) for higher order operations (independent problemsolving).

This paradigm is empowering because it holds open the possibility that subordinates can develop within the demands of the system, whether that be a course, a curriculum, a job, the family or some other organizational form. In this respect it honors the developmental tradition in learning, summed up so ably by one of our own members, Rita Weathersby and her colleague, Jill Tarule, in 1980 . On that note, I urge 
that we suspend methodological nitpickery in favor of attending to the direction of their thought, sufficiently well documented by hard evidence. They honor the Jamesian against premature judgments about other peoples' experience. The paradigm does not predict the rate if growth for anyone, but assumes that growth is attainable by most, if not all.

Faculty teaching behavior, within the terms, is disempowering because it is so fixated at the left end of model in Table III. The psychological reaction to authorization, uni-dimensional, and oneway communication structures tends strongly, for most students, to reinforce a sense of dependence, even helplessness, in the discipline. A low order of learning occurs. As a meta-message - one about the entire academic culture-consistent faculty behavior in the left side of the scale undermines those skills necessary to maintain the health of civil libertarian traditions.

The dynamic reciprocal psychological challenge in the empowering paradigm inheres in the struggles to ensure that students gain more control over the search for and definitions of meaning. It lies, therefore, in the subtle interaction of teacher and student in the processes of taking hold and holding on, falling principally on the student, and letting go and giving up, falling mainly on the faculty member. We owe an unrepayable debt to William Perry for describing so beautifully how the dynamic works and for reminding us that the essential strategies of teaching for learning are individualizing, structuring, challenging, pushing and pulling, and, most critically, supporting empathetically, perhaps empathically. In these respects, the model honors the civil libertarian, egalitarian, and democratic tradition.

Not only does the paradigm suggest that effective instruction is multi-dimensional, it depends upon honest and rigorous evaluation. It suggests, therein, an input-output-outcome model of assessment. It emphasizes learning as the focus. It insists that content and process are equally important in teaching/learning transactions and that the messages of both need to square with one another. And, as a variety of studies of effective classrooms demonstrated, the paradigm as an operational model is as self-fulfilling as the disempowering paradigm. 


\section{A Note on Leadership}

If I am correct in all this, there is still the question as to what we are to do to have cultural impact, to make a difference across most higher education. My responses will be inadequate as an answer, but may form at least the directional beginnings of one which each of us can flesh out later on. I would have us do three things:

1. Become expert in the cultures in which we work. Get to know their operating paradigms, their theories in practice as well as their espoused theories. Square those theories with one another and with the elements of the broader civil libertarian traditions. And become skilled in the techniques which Chris Argyris has spelled out for helping professionals to reconcile the discrepancies in healthful ways.

2. Accept Harold Bridger's challenge to change agents that each develop the courage to act in relation to his or her own development. I think that means, in the dire circumstances facing most professional development efforts in this economy, learning about the transforming uses of power. Look to David McClelland, James MacGregory Burns, Kenneth Eble, Victor Baldridge, and Robert Greenleaf. Become involved in the political decision-making processes of the campus, advocating the developmental message vigorously.

3. Finally, in the best developmental tradition, actively build internal and external resource networks for support, ideas, and material assistance for the important mission we have undertaken. POD, like any network, flourishes with use; it dies from disuse. I believe we need to become much more resourceful at networking than we have ever before.

It falls to us, perhaps even exclusively, to be forces for realizing the empowering promise of higher education, a promise observed more in the breach than in practice.

\section{References}

Argyris, Chris and Schon, D.A. Theory in Practice: Increasing Professional Effectiveness (1975).

Baldridge, J.V. and Associates. Policy Making and Effective Leadership (1978).

Bridger, Harold. 'The Kinds of 'Organizational Development' Required for Working at the Level of the Whole Organization Considered as an Open System, The Proceedings 
of the First European Forum on Organization Development, Aachen, October-November, 1978.

Brown, Arnold. "The Age of Osiris: Tumult and Transformation," The Futurist, April, 1980.

Burns, James MacGregor, Leadership (1978).

Cross, Patricia. "Our Changing Students and Their Impact on Colleges: Prospects for a True Learning Society," Phi Delta Kappen,May, 1980.

de Charms, Richard. Enhancing and Educational Practice (1971).

"From Pawns to Origins: Towards Self- Motivation," in G.S. Lesser, Psychology and Educational Practice (1971).

Personal Causation: The Internal Affective Determinants of Behavior (1968).

Eble, Kenneth. The Art of Administration (1978).

Professors as Teachers (1973).

Greenleaf, Robert K. Servant Leadership: A Journey into the Nature of Legitimate Power and Greatness (1977).

Kerr, Clark, "Human Development \& Education in the '80s,"Inforum (A Professional Journal of the Forum Corporation), Boston, 1980.

Knefelkamp, L. Lee. "Faculty and Student Development in the 80's: Renewing the Community of Scholars," Integrating Adult Development Theory with Higher Education Practice, Current Issues in Higher Education, No. 5, AAHE, 1980.

Likert, Rensis and Jane G. Likert. New Ways to Managing conflict (1976).

McClelland, David. Power: The Inner Experience (1975).

McGregor, Douglas. The Human Side of Enterprise (1960).

Pascale, Richard T. and Anthony G. Athos. The Art of Japanese Management: Applications for American Executives (1981).

Perry, William G., Jr. Forms of Intellectual and Ethical Development in the College Years: A Scheme (1970).

Pfeffer, Jeffrey. Power in Organizations (1981).

Stein, Maurice. The Eclipse of Community (1960).

Tannenbaum, Robert and Warren H. Schmidt. "How to Choose a Leadership Pattern," Harvard Business Review, March-April, 1958.

Weathersby, Rita Preszler and Jill Mattuck Taraule. Adult Development: Implications for Higher Education, AAHR-ERIC/Higher Education Research Report No. 4, 1980.

Yankelovich, Daniel, New Rules: Searching for Self-Fulfillment in a World Turned Upside Down (1981). 